\title{
The Effect of Direct Gas Fluorination on Medical Grade Poly(methyl methacrylate)
}

\author{
Baljit K. Ghatora, Stephen J. Barton, Peter J. S. Foot, Philip Miller Tate \\ Materials Research Centre, Kingston University, Penrhyn Road, Kingston upon Thames, Surrey, UK \\ Email: B.Ghatora@kingston.ac.uk
}

Received 27 August 2014; revised 20 September 2014; accepted 15 October 2014

Copyright (C) 2014 by authors and Scientific Research Publishing Inc.

This work is licensed under the Creative Commons Attribution International License (CC BY). http://creativecommons.org/licenses/by/4.0/

c) (i) Open Access

\begin{abstract}
Medical-grade poly(methyl methacrylate) (PMMA) is extensively employed in the fabrication of a variety of medical implants, including intraocular lenses (IOLs). However, a postoperative complication that leads to the failure of the implanted intraocular lenses has been recently identified. This process, termed calcification, occurs when calcium-containing deposits accumulate on the surface of the IOL. In this study direct gas fluorination was used to modify the surface of PMMA in an attempt to increase the service lifetime of the material in optical applications. PMMA discs exposed to a $20 \%$ fluorine/nitrogen gas mixture for $24 \mathrm{~h}$ were compared with untreated PMMA discs serving as control samples. Over time, both surface-fluorinated and untreated PMMA samples immersed in a simulated aqueous humour solution (SAHS) $\left(\mathrm{pH} 7.4,35^{\circ} \mathrm{C}\right)$ were used to carry out in vitro studies. Attenuated total refractive Infrared spectroscopy (ATR-IR) Scanning electron microscopy (SEM), coupled with Energy dispersive X-ray analysis (EDX), showed that calcium-containing surface deposits were less abundant on surface-fluorinated PMMA compared with the control samples, indicating that the fluorinated surface was acting as a barrier to the deposits. Gravimetric analysis data showed that the decreased rate of diffusion compared with that of a control sample was due to the fluorinated surface.
\end{abstract}

\section{Keywords}

Poly(methyl methacrylate) (PMMA), Surface Fluorination, In Vitro Studies, Simulated Aqueous Humour Solution (SAHS), Medical Polymers

\section{Introduction}

Poly(methyl methacrylate) (PMMA) is a versatile polymer used in a variety of ocular applications ranging from the optics of rigid intraocular lenses (IOLs) to use in the haptics of IOLs. It is important that every material designed to be implanted within the eyes' biological fluids [1] is compatible with this environment. Since the first 
IOL implantation performed by Harold Ridley in November 1949, PMMA still remains the foremost material with which current intraocular lenses are compared to [2]. Even though PMMA implants are being replaced by foldable hydrophilic and silicone IOLs to reduce trauma to the eye during surgery in some countries, PMMA IOLs are still widely used especially in the developing world. Hydrophilic IOLs are made up of a co-polymer of hydroxyethyl methacrylate (HEMA) and methyl methacrylate (MMA), which enable them to have an increased water content to allow for flexibility in the lens.

Cases of post-operative calcification of IOLs, wherein calcium-containing deposits built up on the surface of the IOL, have been reported as early as 1999 [3] [4]. This complication is more apparent in hydrophilic IOLs, possibly due to surface hydroxyl groups of the acrylate polymer undergoing complexation with calcium ions to form nuclei that trigger the growth of crystallites of calcium [5]. This process eventually results in opacification and failure of the IOL following cataract surgery [6] [7]. Calcification is a problem of growing concern as it causes the patients to experience repeat trauma to the eyes when the failed implant has to be removed; however, to date a clear explanation for its mechanism of formation has not yet been agreed. Some proposed that mechanisms included two main classifications of calcification, namely, primary and secondary. Primary calcification is a result of the material itself, whereby any flaws in the material act as nucleation sites to initiate calcium mineralisation [8]; secondary calcification is a result of the ocular environment that the IOL surface has been exposed to, if any pre-existing medical conditions of the patient cause an increase in calcium concentration [9].

There have been substantial studies carried out upon explanted opacified silicone and hydrophilic based IOLs to assess any calcium-containing deposits [10]. However the present in vitro work is the first of its kind studying the calcification of medical-grade PMMA and the application of direct fluorination to hinder the calciferous deposits. This surface modification can be a possible solution for opacification of PMMA based IOLs, which are employed in large numbers, particularly within developing countries.

There are many different methods in which a polymer surface can be usefully modified, with fluorination being a technique currently in use with contact lenses [11]. Elemental fluorine has successfully been employed within petrol tanks to enhance the barrier properties of high density polyethylene (HDPE). This direct fluorination surface modification effectively reduces the loss of petrol caused by diffusion of liquids through the tank walls [12]. An effective way to fluorinate a material is by the substitution of the hydrogens, attached to carbon, with the use of an electrophilic fluorinating reagent. With one of the least expensive and most reactive agents being fluorine gas itself [13]. It was therefore proposed that fluorinating the materials used for intraocular lenses might improve their surface properties and keep the bulk properties intact. In previous literature, modifications applying direct gas fluorination to modify a minimal surface depth of IOLs have been used with the aim of reducing bacterial adhesion [14], however direct gas fluorination with the aim of hindering calcification has not been studied before.

\section{Experimental Details}

\subsection{Materials Used}

High molecular weight medical-grade PMMA discs $(2.5 \mathrm{~mm}$ thickness and $10 \mathrm{~mm}$ diameter) were used in this study. $50 \%$ of the discs were exposed to a 0.8 bar pressure of $20 \%$ fluorine/nitrogen gas mixture in a stainless steel chamber by Solvay Fluor, Germany. Samples were left in the chamber for 24 hours, and the chamber was periodically shaken to achieve fluorination all over the surface. The remainder of the untreated PMMA discs was used as controls.

Simulated aqueous humour solution (SAHS) was prepared from five Phosphate Buffered Saline (PBS) tablets (Fischer Scientific) dissolved in distilled water (1L) to make up the master solution at $37^{\circ} \mathrm{C}$. The following materials were then added: $\mathrm{NaCl}(7.1943 \mathrm{~g}), \mathrm{NaHCO}_{3}(1.6801 \mathrm{~g}), \mathrm{KCl}(0.2982 \mathrm{~g}), \mathrm{MgCl}_{2} \cdot 6 \mathrm{H}_{2} \mathrm{O}(0.1322 \mathrm{~g})$, $\mathrm{Na}_{3} \mathrm{PO}_{4}(0.16801 \mathrm{~g}), \mathrm{CaCl}_{2} \cdot 2 \mathrm{H}_{2} \mathrm{O}(0.1911 \mathrm{~g}), \mathrm{Na}_{2} \mathrm{SO}_{4}(0.1846 \mathrm{~g})$, urea $(0.3663 \mathrm{~g})$, glucose $(0.5044 \mathrm{~g})$, alanine $(0.0223 \mathrm{~g})$, serine $(0.0841 \mathrm{~g})$, valine $(0.0293 \mathrm{~g})$ (all from Sigma-Aldrich) and sodium lactate $(0.5043 \mathrm{~g})$ (Alfa Aesar). $1 \%$ sodium hyaluronate in PBS was prepared by dissolving sodium hyaluronate $(0.2500 \mathrm{~g})$ in $25 \mathrm{ml}$ of PBS. $110 \mu \mathrm{L}$ of this was added to the master solution of SAHS. $450 \mu \mathrm{L}$ of a $30 \%$ albumin solution was also added to the master solution of SAHS using a pipette, and the solution was mixed thoroughly. It was then filtered using Whatman \#6 filter paper, and the $\mathrm{pH}$ was adjusted to be between 6.8 and 7.0 with a few drops of hydrochloric acid (1M). The final solution was then incubated in the oven at $37^{\circ} \mathrm{C}$.

The untreated and surface-fluorinated PMMA discs were immersed in SAHS and removed for analysis at 
staggered time points over a period of two weeks. Prior to all analysis, carried out at room temperature, superficial fluid was removed by blotting the PMMA disc onto filter paper.

\subsection{Gravimetric Analysis}

The treated and untreated PMMA discs were immersed in SAHS $(10 \mathrm{~mL})$ and removed periodically for changes in mass to be recorded. The percentage weight gain/loss of the untreated and surface treated PMMA discs $\left(M_{t}\right)$ immersed in SAHS was measured as a function of time using Equation (1), where $W_{d}$ denotes the initial weight of the sample prior to immersion in the SAHS, and $W_{w}$ is the weight of sample after immersion in SAHS.

$$
M_{t}(\%)-\frac{M_{w}-M_{d}}{M_{d}} \times 100
$$

Equation (1) The percentage weight gain/loss of PMMA samples, measured as a function of time

\subsection{Surface Analysis via Scanning Electron Microscopy (SEM) and Energy Dispersive X-Ray Spectroscopy (EDX)}

The discs were prepared for analysis by mounting onto the SEM slide and coating the sample with thin, sputtered gold plating. Images were taken of those areas on the discs which had apparent deposits, using a Zeiss EVO 50 SEM with a beam current of $1.5 \mathrm{nA}$. The discs were then analysed using EDX (with a detection limit of $0.3-0.5 \mathrm{wt} \%$ ), and the peaks labelled on the spectra, including the expected one for Au.

\subsection{Attenuated Total Reflectance Infrared (ATR-IR)}

ATR-IR was carried out on the PMMA discs using a Perkin Elmer Metler Toledo ATR-IR instrument. Once the background scan has been obtained, the sample of PMMA was placed onto the crystal. The spectrum was recorded from 4000 to $650 \mathrm{~cm}^{-1}$ at a resolution of $4 \mathrm{~cm}^{-1}$ using scan Number 32 .

\section{Results and Discussion}

An ATR-IR scan of the surface treated PMMA was compared against the untreated PMMA to assess the degree of fluorination (Figure 1).

The main noted difference is the disappearance of the $\mathrm{CH}$ peaks at around $3000 \mathrm{~cm}^{-1}$, due to the substitution of hydrogen atoms with fluorine, via the gas fluorination process. This can also be confirmed by the strong peaks in the region $1000-1400 \mathrm{~cm}^{-1}$ which are characteristic of the $\mathrm{CF}_{3}$ and $\mathrm{CF}_{2}$ bonds that mask the C-O stretch. The differences that can be seen are identified in Table 1.

A point of interest is the peak that appeared adjacent to the $\mathrm{C}=\mathrm{O}$ peak, at around $1750-1720 \mathrm{~cm}^{-1}$. It is well known that fluorination can be accompanied by oxidation or often referred to as oxy-fluorination [15]. The oxygen impurity present within the fluorine gas can possibly result in the formation of acyl fluoride groups

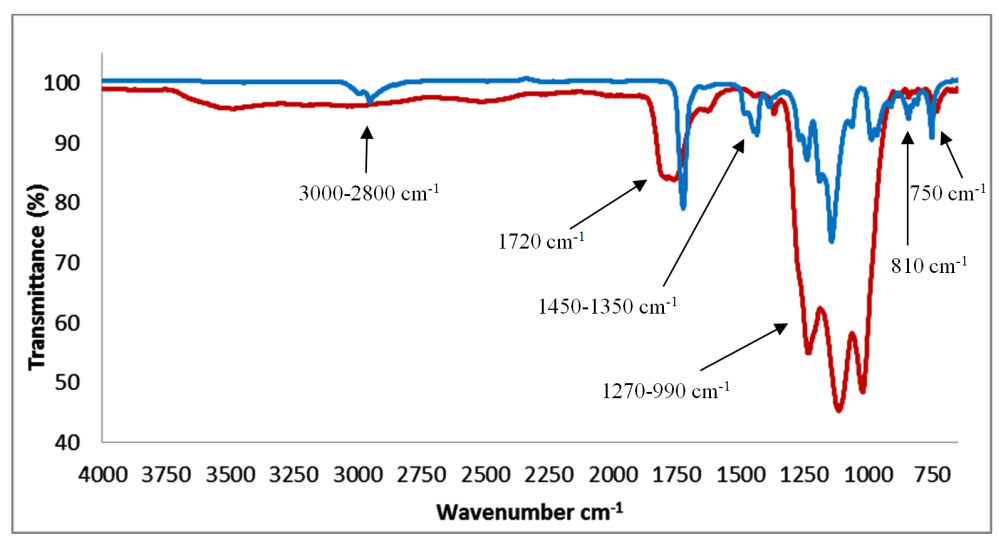

Figure 1. ATR-IR of surface treated PMMA (red) and untreated PMMA (blue). 
(-COF), which would be seen at $1850 \mathrm{~cm}^{-1}$; however the ATR-IR spectrum of surface fluorinated PMMA shown in Figure 1 indicates no presence of acyl fluoride groups on the surface. Nevertheless these acyl fluoride groups, when exposed to moisture become hydrolysed to form carboxylic acid groups (-COOH), which would be identified through a $\mathrm{C}=\mathrm{O}$ peak at $1750 \mathrm{~cm}^{-1}$. If we refer back to the ATR-IR spectra in Figure 1, a shoulder peak seen adjacent to the $\mathrm{C}=\mathrm{O}$ vibration at $1750-1720 \mathrm{~cm}^{-1}$ on the surface fluorinated PMMA has been identified.

Depending upon the reaction conditions of gas fluorination, the depth to which the fluorine atoms penetrate into the PMMA can be adjusted. Therefore, it is possible that any un-reacted acyl fluoride groups (-COF) that are trapped within the polymer matrix may not convert freely to carboxylic acid groups (- $\mathrm{COOH})$ as the fluorinated surface layer acts as a barrier to water penetrating within the polymer matrix. After the surface fluorinated discs had been immersed within the SAHS, they were analysed again using ATR-IR to determine whether any surface changes had occurred as a result of the immersion (Figure 2).

The infrared spectrum clearly shows that after immersion within the SAHS the surface fluorinated PMMA was altered. The C-F region at $1270-990 \mathrm{~cm}^{-1}$ initially decreased in intensity up until 288 hours, after which point it began increasing again. This could possibly be due to short polymer oligomers formed during the fluorination process, which when present upon the surface of the PMMA would mask the C-F stretch.

At the same time there is a re-appearance, after 120 hours immersion, followed by a disappearance after 696 hours, of the methyl $\mathrm{CH}_{3}$ and $\mathrm{CH}_{2}$ peaks at around $3000 \mathrm{~cm}^{-1}$. These surface changes may be due to the methylcontaining oligomers that are close to the surface. After 696 hours of immersion in SAHS, the surface methyl peaks present from any oligomers disappear, which is also matched with an increase in intensity and broadness of the C-F stretch. This again could be suggestive of the fact that the oligomers had been washed off the surface after a period of immersion. It could also be argued that the changes in the surface were due to any proteins/ amino acids that may have deposited on the surface from the SAHS, but as there are no N-H peaks detected on the ATR-IR spectra, this theory is not a possible reason.

The diffusion behaviour of surface fluorinated and untreated PMMA was investigated for up to two weeks,

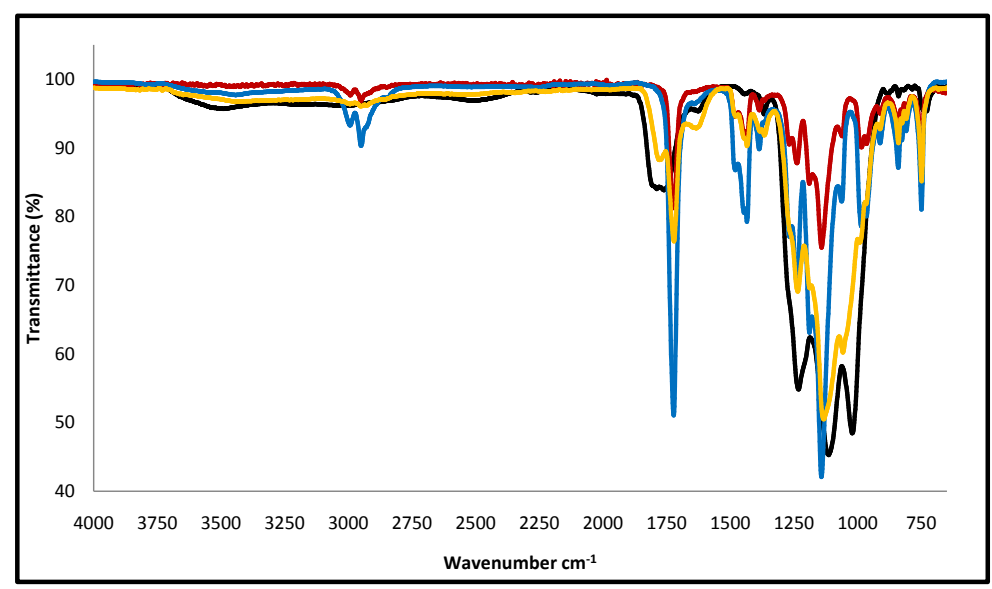

Figure 2. ATR-IR spectra of surface treated PMMA (black) after immersion within SAHS for 120 hours (red), 288 hours (blue) and 696 hours (yellow).

Table 1. Identification of peaks seen in a surface fluorinated PMMA sample.

\begin{tabular}{cc}
\hline WAVENUMBER CM & INDENTIFICATION \\
\hline $3000-2800$ & Disappearance of CH \\
1720 & $\mathrm{C}=\mathrm{O}$ stretching \\
$1450-1350$ & Disappearance of C-H bending \\
$1270-990$ & C-F stretching masking $\mathrm{C}=\mathrm{O}$ \\
810,750 & $\mathrm{CH}_{2}$ rocking intensity decreased with a noted broader peak \\
\hline
\end{tabular}


and the associated mass changes are shown in Figure 3. As the gravimetric analysis was only carried out over a short period, there was not sufficient data to calculate the diffusion coefficients, as a maximum absorption $\left(M_{\infty}\right)$ point has not been reached [16] [17].

There is an initial rapid increase in mass of both the untreated and treated PMMA samples after immersion in the SAHS. Current literature suggests two main factors affecting the process by which water may diffuse/absorb into glassy polymer networks such as PMMA. The polymer chains may be arranged in ways which cause significant free volume (void spaces) to exist within the polymer network. It is within these spaces that the water molecules from the SAHS solution diffuse into the polymer and cause an increase in mass of PMMA immersed within a solution. The second factor favouring the water molecules' penetration into the PMMA polymer network is hydrogen bonding to the polar oxygen sites on the MMA side-groups [18].

It is proposed that water molecules bonded close to the surface of the PMMA can attract ions to adhere to the surface. Previous studies have shown that diffusion triggers the process of calcification, whereby calcium containing deposits may be noticed on the PMMA surface after just seven days [19]. Therefore if we are able to hinder diffusion we may in turn delay calcification, or even prevent it.

Upon looking closely at the typical gravimetric data for the surface treated PMMA, it is clear that there was an initial decrease in the mass of the samples immersed within the SAHS in the first 24 hours. This could be accounted for by the fluorination process which may have damaged the polymer, and as seen in the ATR-IR, any oligomers present may have been washed off the surface after immersion thereby showing a decrease in weight in the initial periods. Fluorine reacts with hydrocarbon chains such as those at the surface of PMMA by a free-radical chain reaction mechanism in an exothermic reaction whereby hydrogen fluoride (HF) gas is produced as a by-product, as shown in Scheme 1.1 and Scheme 1.2.

If there was any oxygen present whilst the PMMA samples were exposed to the fluorine gas, this too could have caused fragmentation of the carbon backbone of PMMA. However, using an oxygen-free environment is very difficult as trace amounts of oxygen are usually present in commercial fluorine gas [20] [21]. Therefore, it is possible that the degradation of the carbon-carbon backbone of PMMA results in the production of short chain oligomers or other small molecules at the surface which would have been washed off after immersion within the SAHS, accounting for the initial weight loss.

It is also possible that oxygen, present as an impurity, reacted with the free radicals formed in Scheme $\mathbf{1 . 1}$ to form peroxy radicals. Once immersed in the SAHS, these peroxy radicals will undergo hydrolysis or H-abstraction, forming carboxylic acid groups (Scheme 1.3) and this again would cause a decrease in mass.

In an attempt to establish an accurate estimate of the diffusion rate, the surface treated PMMA gravimetric data was corrected by taking into account the amount of mass that had been washed off/lost from the sample, and typical values are plotted in Figure 4.

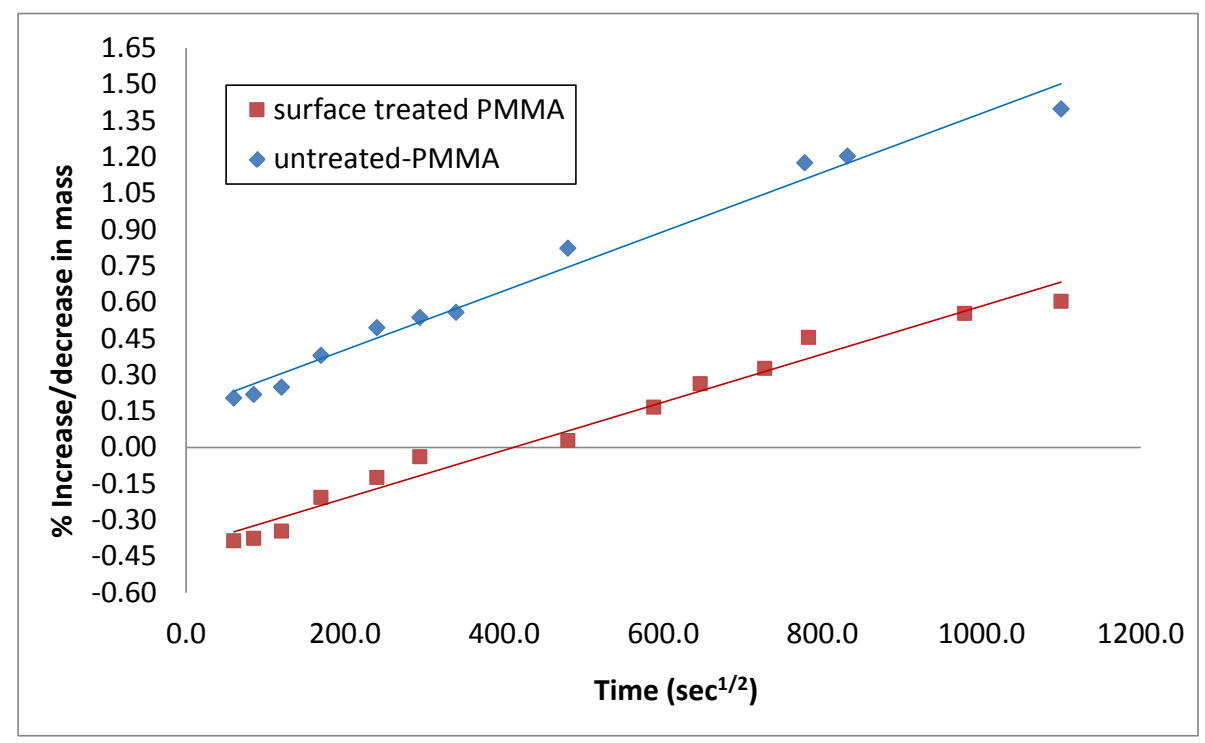

Figure 3. Graphical representation of the average \% increase/decrease in mass of untreated (n $=3)$ and surface-fluorinated PMMA $(n=3)$. 


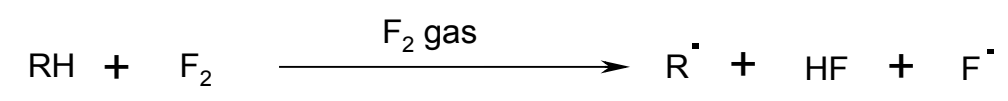

Scheme 1.1. Fluorine gas reacting with hydrocarbon chain.

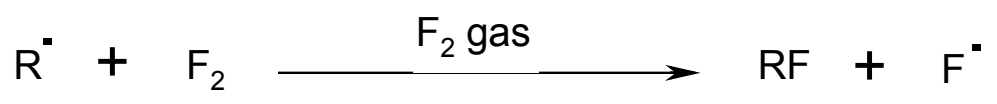

Scheme 1.2. Chain propagation of radicals.

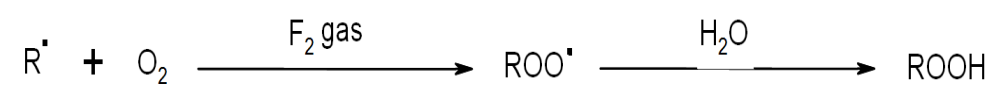

Scheme 1.3. Reaction mechanism for the formation of carboxylic acid
group.

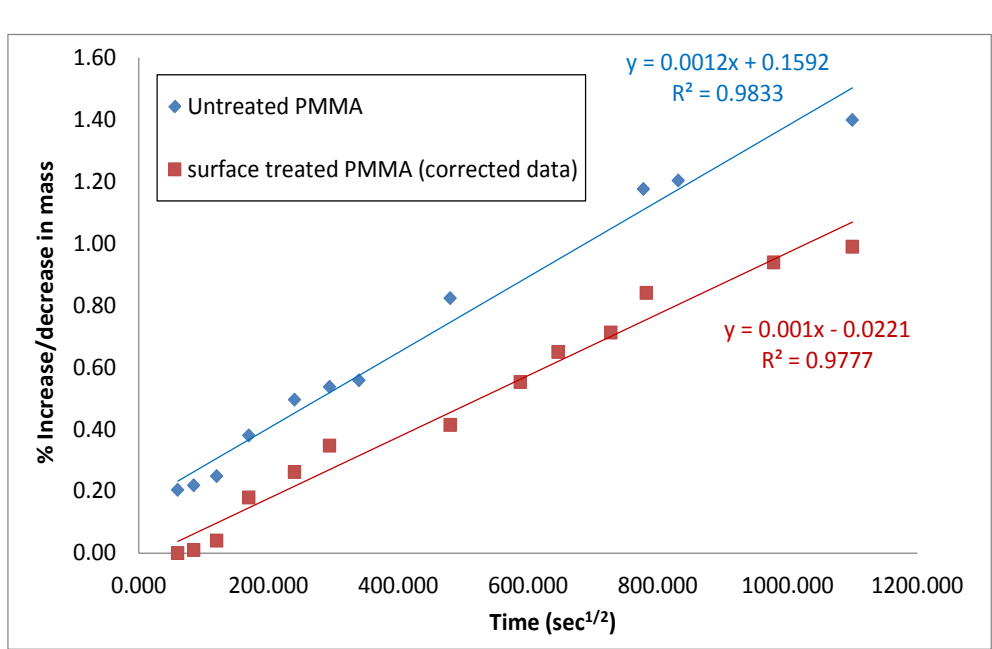

Figure 4. Graphical representation of the average corrected \% increase/decrease in mass of the untreated $(n=3)$ and surface fluorinated PMMA $(n=3)$.

The corrected data does indicate that the rate of diffusion within the surface treated PMMA is slightly slower, but not significantly slower, than the untreated PMMA. However as the $M_{\infty}$ point was not reached it is not possible to determine diffusion coefficients, but it is reasonable to conclude that if the diffusion rate is linked to increases in mass, then diffusion will occur slightly slower in surface-treated PMMA than untreated PMMA, as depicted in Figure 4.

In order to assess whether the diffusion process was triggering calcification, areas of the immersed untreated and surface treated PMMA samples were examined using SEM analysis, and images were captured of areas that had what appeared to be white deposits on the surface (Figure 5). The untreated PMMA after 7 days exhibited definite crystal-like structures, which when analysed using EDX were identified as calcium-containing deposits.

These initial deposits are able to grow over time and enter into the IOL matrix [22] which could cause primary calcification of the IOL. The Al and Pd peaks can be accounted for by pollutants in the atmosphere [23], and other elements such as $\mathrm{Na}, \mathrm{Mg}$ and $\mathrm{Cl}$ which are present in the SAHS. The other elements that were detectable suggest that there is a possibility of more than one mechanism being involved in deposit formation [24], but in this study calcification is the mechanism of interest.

The untreated PMMA was analysed and areas on the surface of the IOL were captured in images using SEM (Figure 6) as comparisons. It is apparent that the fluorination had eliminated the ability of calcium containing 

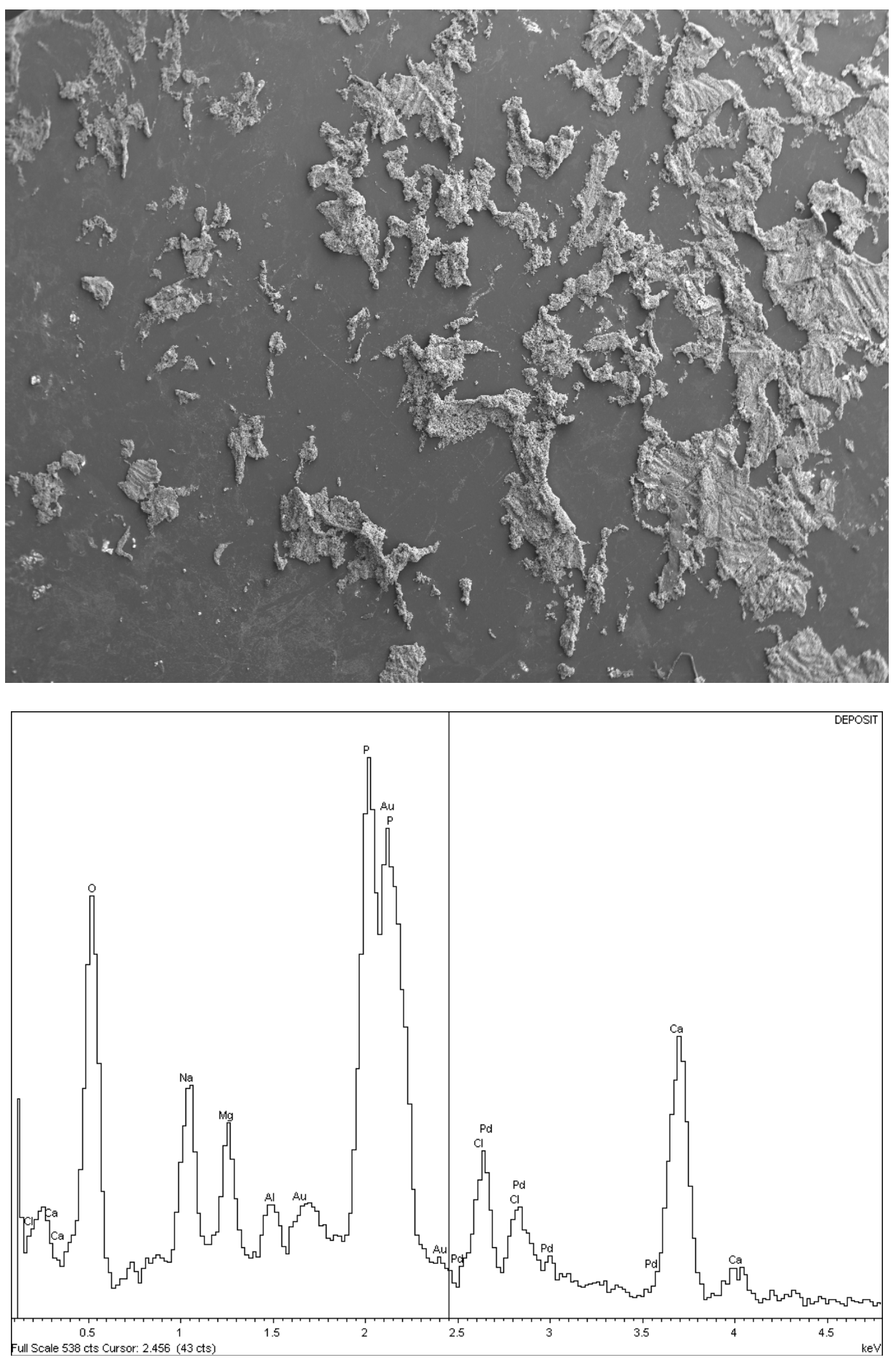

Figure 5. SEM (above) and EDX (bottom) of surface deposits on untreated PMMA disc 7 days after immersion within SAHS. EDX histogram shows Ca and P peak.

deposits to adhere to the surface as the images depicted a much clearer looking surface, containing none or very few deposits. Any regions which had what appeared to be deposits were analysed using EDX and only F, C and $\mathrm{O}$ peaks were detected, which are from the bulk material itself. This shows that the fluorination process was successful, and that the fluorination had created a barrier that not only stopped calcification, but also reduced the moisture uptake. 

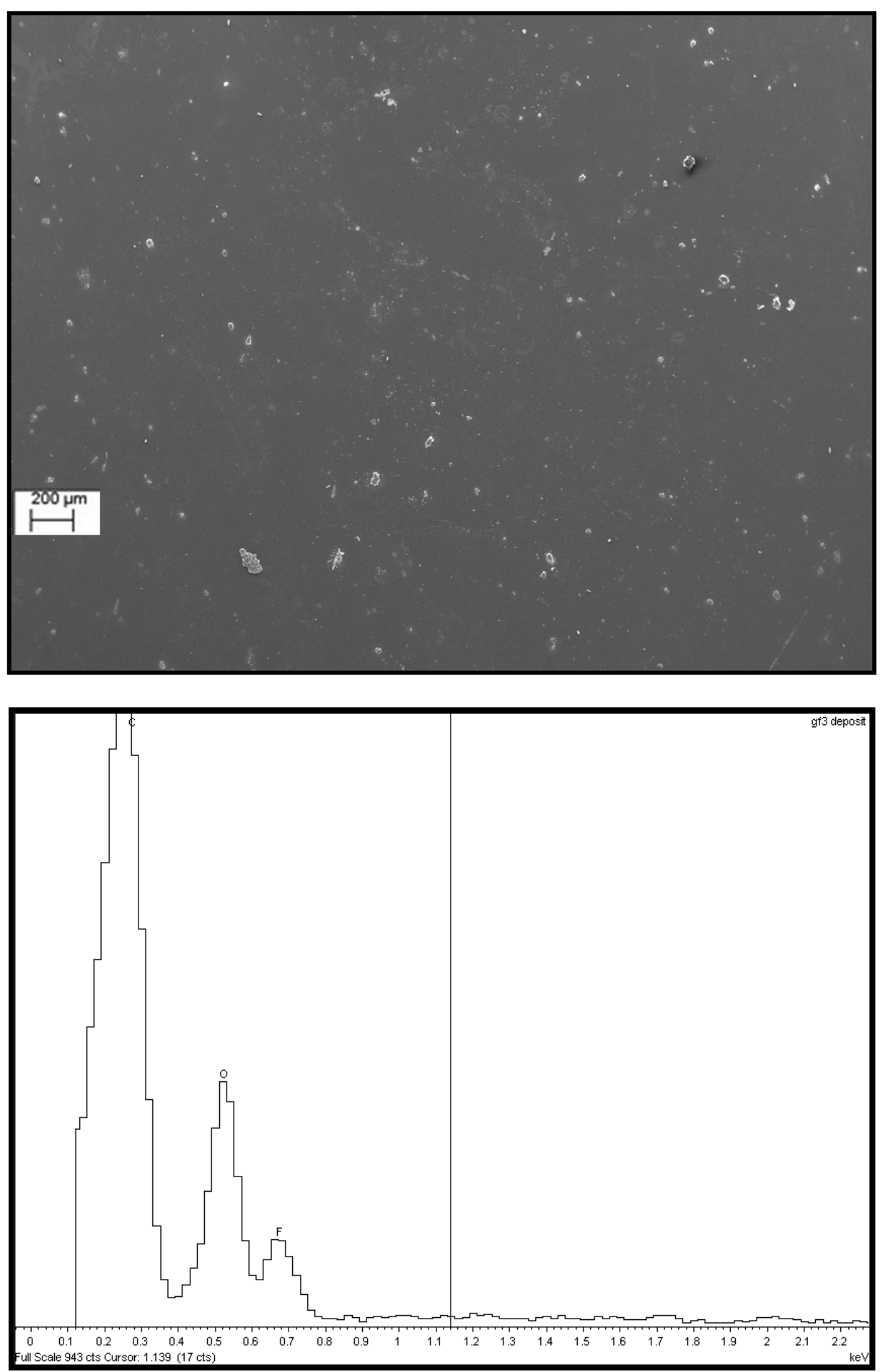

Figure 6. SEM (top) and EDX (bottom) of surface deposits on Surface treated PMMA disc after 12 days immersed within SAHS. EDX histogram shows the presence of the fluorine peak alone.

\section{Conclusion}

PMMA material of the type used for intraocular lenses was surface-treated via direct gas fluorination. Modified and unmodified discs were placed into simulated aqueous humour and incubated in a temperature controlled 
oven at $35^{\circ} \mathrm{C}$. Initially the gravimetric analysis indicated that fluorination had caused some structural degradation in the PMMA surface, which led to an initial decrease in mass of the fluorinated samples. Once the data had been corrected to take into account any initial weight loss, the surface fluorination process produced a barrier effect on the PMMA discs, which caused a slower rate of diffusion of water into the polymer network, compared with the untreated PMMA. This was accompanied by a reduction in the deposits that was noted on the surface of the fluorinated PMMA. The results support the theory that diffusion of water into the polymer free volume and binding at the polar oxygen sites provides a more favourable environment for calcification to initiate. Surface fluorination successfully hinders the formation of calcium-containing surface deposits. Therefore, it is a method that may in the future be applied to intraocular lenses to reduce the likelihood of repeat implant surgery.

\section{References}

[1] Jaffe, M., Ophair, Z. and Pai, V. (2003) Biorelevant Characterization of Biopolymers. Thermochimica Acta, 396, 141152. http://dx.doi.org/10.1016/S0040-6031(02)00524-5

[2] Kohnen, T. (1996) The Variety of Foldable Intraocular Lens Materials. Journal of Cataract Refractive Surgery, 22, 1255-1259. http://dx.doi.org/10.1016/S0886-3350(96)80079-4

[3] Werner, L. (2008) Calcification of hydrophilic Acrylic Intraocular Lenses. American Journal of Ophthalmology, 146, 341-343. http://dx.doi.org/10.1016/j.ajo.2008.05.011

[4] Werner, L. (2007) Causes of Intraocular Lens Opacification or Discoloration. Journal of Cataract Refractive Surgery, 33, 713-726. http://dx.doi.org/10.1016/i.jcrs.2007.01.015

[5] Dalas, E., Kallitsis, J.K. and Koutsoukos, P.G. (1991) Crystallization of Hydroxyapatite on Polymers. Langmuir, 7, 1822-1826.

[6] Bucher, P.J.M., Buchi, E.R. and Daicker, B.C. (1995) Dystrophic Calcification of an Implanted Hydrpxyethylmethacrylate Intraocular Lens. Arch Opthalmology, 113, 1431-1435. http://dx.doi.org/10.1001/archopht.1995.01100110091031

[7] Olson, R.J., Caldwell, K.D. and Crandall, A.S. (1998) Intraoperative Crystallisation on the Intraocular Lens Surface. American Journal of Ophthalmology, 126, 177-184. http://dx.doi.org/10.1016/S0002-9394(98)00076-2

[8] Werner, L., Hunter, B., Stevens, S., Chew, J.J. and Mamalis, N. (2006) Role of Silicon Contamination on Calcification of Hydrophilic Acrylic Intraocular Lenses. American Journal of Ophthalmology, 141, 35-43. http://dx.doi.org/10.1016/j.ajo.2005.08.045

[9] Dorey, M.W., Brownstein, S., Hill, V.E., Mathew, B., Botton, G., Kertes, P.J. and El-Defrawy, S. (2003) Proposed Pathogenesis for the Delayed Postoperative Opacification of the Hydroview Hydrogel Intraocular Lens. American Journal of Ophthalmology, 135, 591-598. http://dx.doi.org/10.1016/S0002-9394(02)02154-2

[10] Werner, L. (2007) Causes of Intraocular Lens Opacification or Discoloration. Journal of Cataract \& Refractive Surgery, 33, 713-726. http://dx.doi.org/10.1016/j.jcrs.2007.01.015

[11] Nicolson, P.C. and Vogt, J. (2001) Soft Contact Lens Polymers: An Evolution. Biomaterials, 22, 3273-3283.

[12] Kharitonov, A.P. (2000) Practical Applications of the Direct Fluorination of Polymers. Journal of Fluorine Chemistry, 103, 123-127. http://dx.doi.org/10.1016/S0022-1139(99)00312-7

[13] Sandford, G. (2007) Elemental Fluorine in Organic Chemistry. Journal of Fluorine Chemistry, 128, 90-104. http://dx.doi.org/10.1016/j.jfluchem.2006.10.019

[14] Kodjikian, L., Burillon, C., Chanloy, C., Bostvironnois, V., Pellon, G., Mari, E., Freney, J. and Roger, T. (2002) In Vivo Study of Bacterial Adhesion to Five Types of Intraocular Lenses. Investigative Ophthalmology \& Visual Science, 43, 3717-3721.

[15] Du Toit, F.J., Sanderson, R.D., Engelbrecht, W.J. and Wagener, J.B. (1995) The Effect of Surface Fluorination on the Wettability of High Density Polyethylene. Journal of Fluorine Chemistry, 74, 43-48. http://dx.doi.org/10.1016/0022-1139(94)03218-O

[16] Magee, T.R.A. and Richardson, P.S. (2007) Modelling Water Absorption of Pasta during Soaking. Journal of Food Engineering, 82, 600-607. http://dx.doi.org/10.1016/j.jfoodeng.2007.03.018

[17] Thomas, N.L. and Windle, A.H. (1980) A Deformation Model for Case II Diffusion. Polymer, $21,1031$. http://dx.doi.org/10.1016/0032-3861(80)90316-X

[18] Moghbelli, E., Banyay, R. and Sue, H. (2014) Effect of Moisture Exposure on Scratch Resistance of PMMA. Tribology International, 69, 46-51. http://dx.doi.org/10.1016/j.triboint.2013.08.012

[19] Zainuddin, Z., Chirila, T.V., Hill, D.J.T. and Whittaker, A.K. (2005) Study of the Calcification of PHEMA Hydrogels Using a Two Compartment Permeation Cell. Journal of Molecular Structure, 739, 199-206. 
[20] Hayes, L.J. (1976) Surface Energy Of Fluorinated Surfaces. Journal of Fluorine Chemistry, 8, 69-88. http://dx.doi.org/10.1016/S0022-1139(00)82900-0

[21] Le Roux, J.D., Paul, D.R., Arendt, M.F., Yuan, Y. and Cabasso, I. (1994). Surface Fluorination of Poly(phenylene oxide) Composite Membranes: Part II. Characterization of the Fluorinated Layer. Journal of Membrane Science, 90, 37-53. http://dx.doi.org/10.1016/0376-7388(94)80032-4

[22] Buchen, S.Y., Cunanan, C.M., Gwon, A., Weinschenk, J.L., Gruber, L. and Knight, P.M. (2001) Assessing Intraocular Lens Calcification in an Animal Model. Journal of Cataract Refract Surgery, 27, 1473-1484. http://dx.doi.org/10.1016/S0886-3350(01)00842-2

[23] Tilch, J., Schuster, M. and Fresenius, S. (2000) Determination of Palladium in Airborne Particulate Matter. Journal of Analytical Chemistry, 367, 450-453. http://dx.doi.org/10.1007/s002160000380

[24] Lai, J.Y., Chen, K.H., Hsu, W.M., Lee, T.H. and Lin, S.Y. (2005) Multiple Elements in the Deposits of Opacified Hydroview Intraocular Lens. American Journal of Ophthalmology, 139, 1123-1125. http://dx.doi.org/10.1016/j.ajo.2004.11.052 
Scientific Research Publishing (SCIRP) is one of the largest Open Access journal publishers. It is currently publishing more than 200 open access, online, peer-reviewed journals covering a wide range of academic disciplines. SCIRP serves the worldwide academic communities and contributes to the progress and application of science with its publication.

Other selected journals from SCIRP are listed as below. Submit your manuscript to us via either submit@scirp.org or Online Submission Portal.
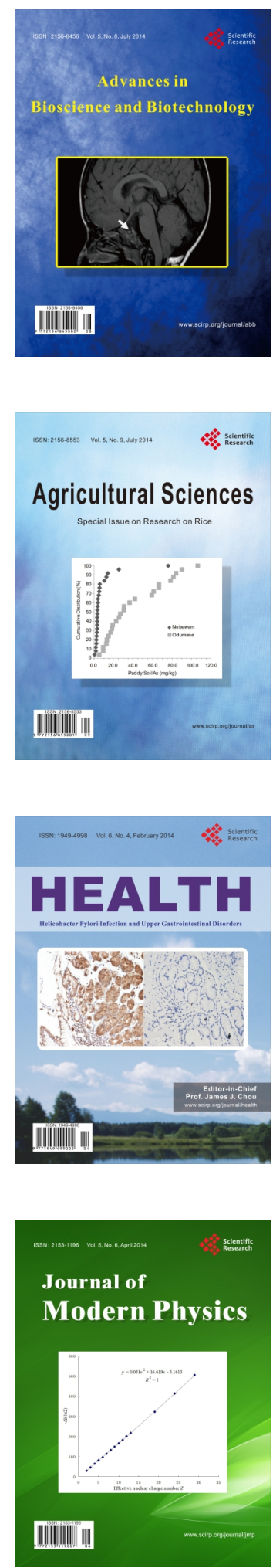
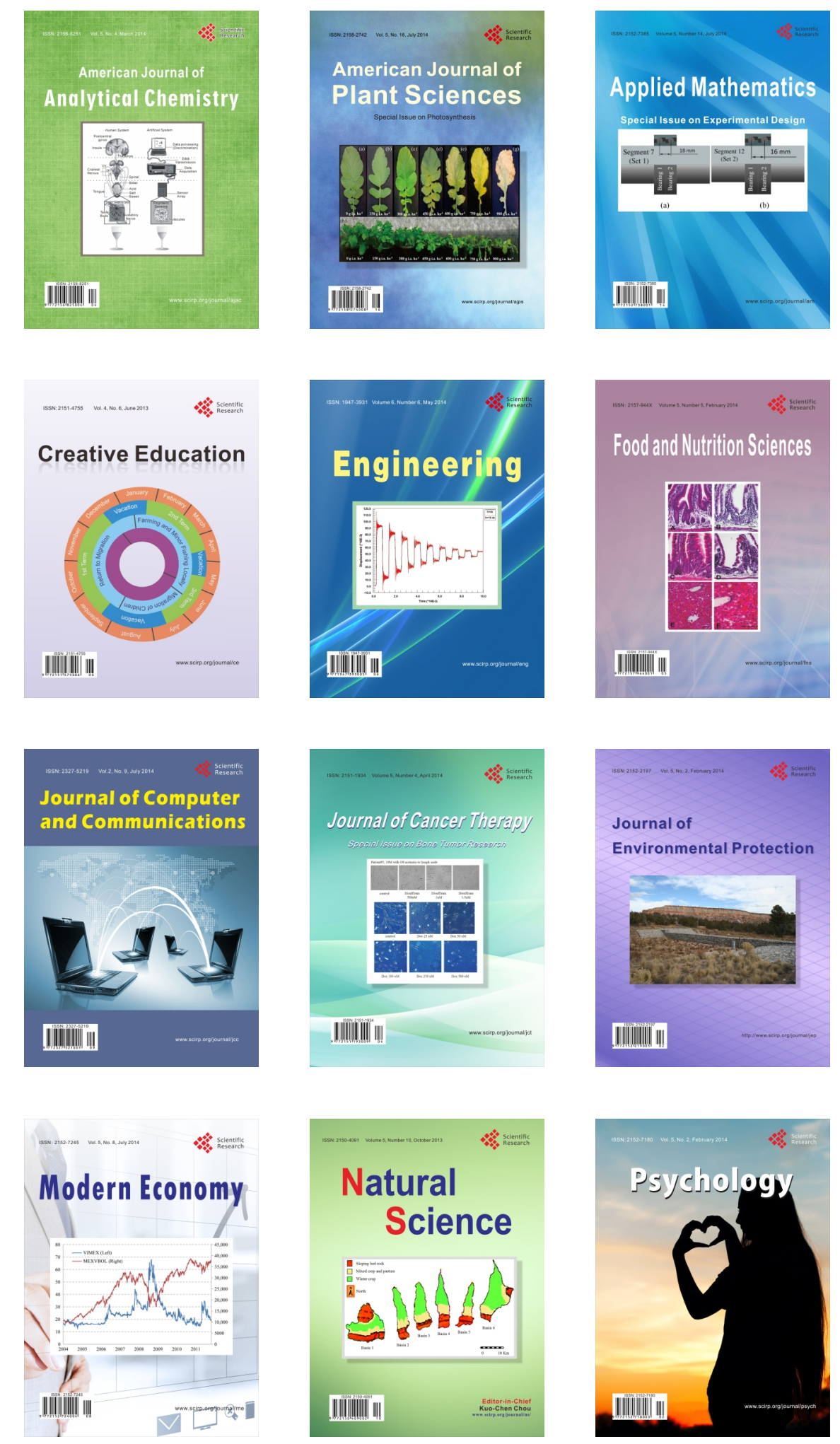